$9 \quad{ }^{2}$ State Key Laboratory of Environmental Chemistry and Ecotoxicology, Research

\section{Digestive Elimination of Coexisting Microplastics for Determination of Particulate Black Carbon in Environmental Waters} Center for Eco-Environmental Sciences, Chinese Academy of Sciences, P. O. Box 2871, Beijing 100085, China. ${ }^{3}$ State Key Laboratory of Heavy Oil Processing, College of Chemical Engineering and Environment, China University of Petroleum-Beijing, Beijing, 102249, China

${ }^{4}$ University of Chinese Academy of Sciences, Beijing 100049, China.

5

16

\section{Total figures: 6}

\section{Table: 1}

\section{Total pages: 8}

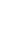

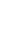

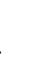
5

* Corresponding author.

Tel.: +86-10-62849192; Fax: +86-10-62849192;

E-mail: jfliu@rcees.ac.cn 

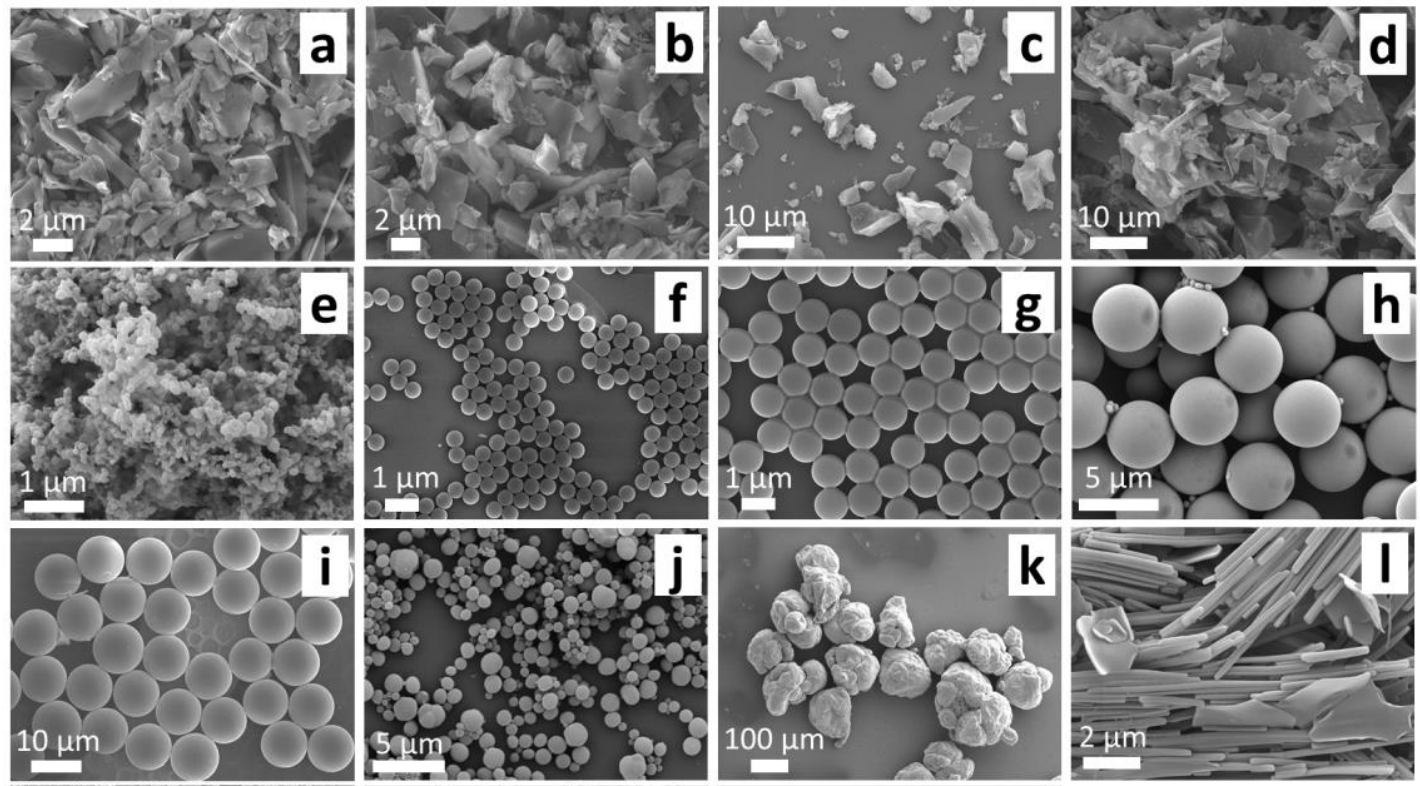
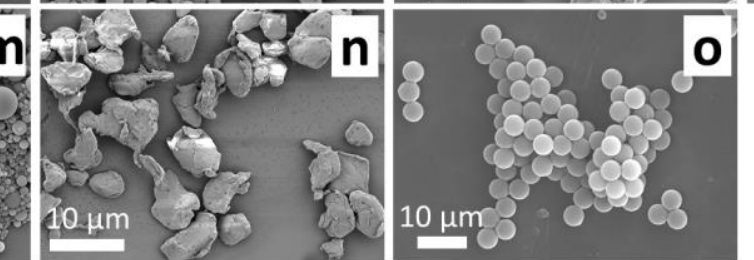

Figure S1. SEM characterization of PBC and MPs. PBC prepared from maize straw with pyrolysis temperature of $400(\mathrm{PBC}-1,0.4-60.2 \mu \mathrm{m})(\mathrm{a})$ and $500{ }^{\circ} \mathrm{C}(\mathrm{PBC}-2,0.5$ - $13.2 \mu \mathrm{m})(\mathbf{b})$, respectively, corncob (PBC-3, $0.3-19.6 \mu \mathrm{m})(\mathbf{c})$, sesame straw (PBC4, $0.4-44.8 \mu \mathrm{m})(\mathbf{d})$ and collected from kitchen $(\mathrm{PBC}-5,0.2-33.0 \mu \mathrm{m})(\mathbf{e})$. PS particles with diameter of $0.48 \pm 0.02 \mu \mathrm{m}(\mathbf{f}), 1.2 \pm 0.1 \mu \mathrm{m}(\mathbf{g}), 2.1 \pm 0.1 \mu \mathrm{m}(\mathbf{h})$ and $8.8 \pm 0.4 \mu \mathrm{m}$ (i). PVC particles with size of $0.2-2.1 \mu \mathrm{m}(\mathbf{j})$ and $46-163 \mu \mathrm{m}(\mathbf{k})$. PP rods with size of $1.0-19.0 \mu \mathrm{m}(\mathbf{l})$. PE particles with size of $0.60-4.3 \mu \mathrm{m}(\mathbf{m})$. PET particles with size of $8.8-51.2(\mathbf{n})$. PMMA particles with size of $416 \pm 24 \mathrm{~nm}(\mathbf{0})$. 


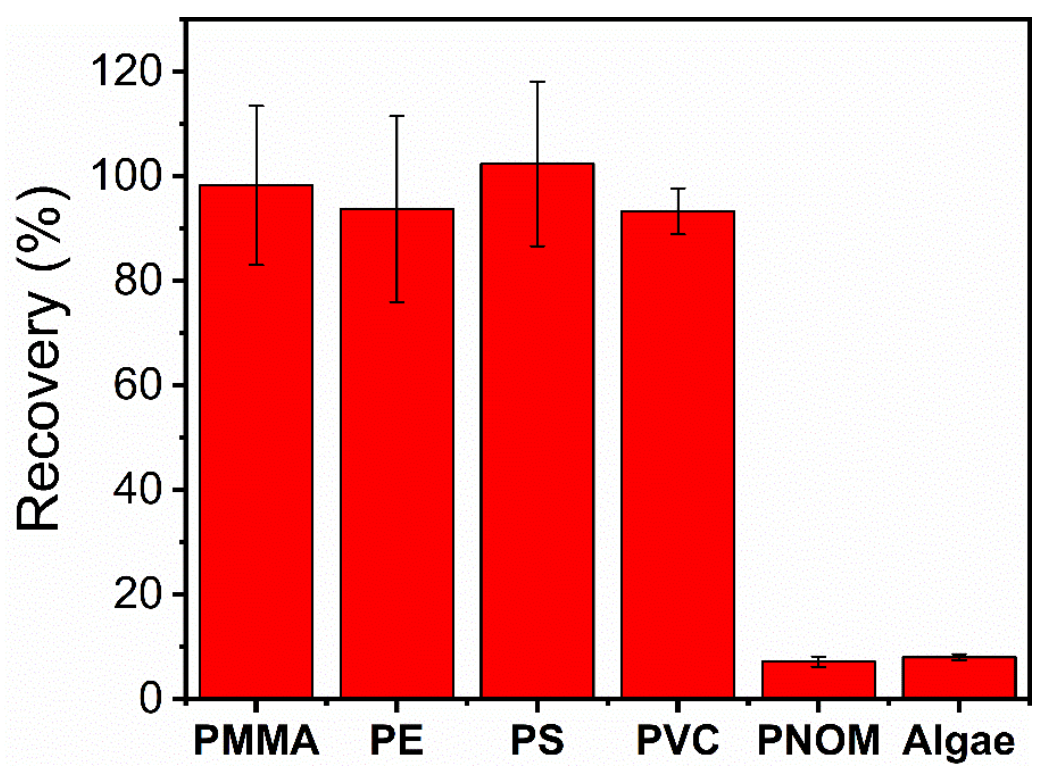

40 Figure S2. Fenton digestion of particulate natural organic matter (PNOM) and chlorella 41 vulgaris algae. PMMA, PE, PS, PVC, PNOM and algae were spiked into pure water 42 with final concentration of 400, 500, 200, 250, 164 and $699 \mu \mathrm{g} \mathrm{C} / \mathrm{L}$, and then were 43 filtered by glass fiber membranes. The membranes retained with MPs or other nBC44 OMs were subjected to Fenton digestion followed by TOC determination after drying. 45 


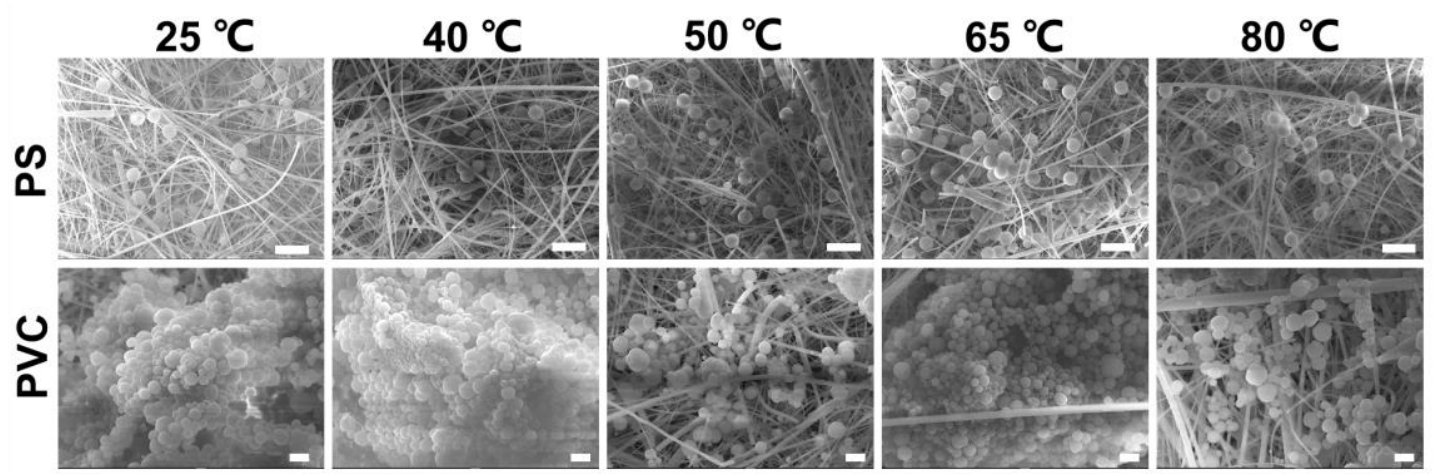

48 Figure S3. SEM characterization of PS and PVC. PS and PVC particles were added 49 into pure water and incubated in water bath at a respective temperature of $25,40,50$, $50 \quad 65$ and $80{ }^{\circ} \mathrm{C}$ for 3 hours, and then their morphologies were characterized by SEM after 51 filtration with glass fiber membrane. The scale bars in PS and PVC groups are 10 and $52 \quad 2 \mu \mathrm{m}$. 


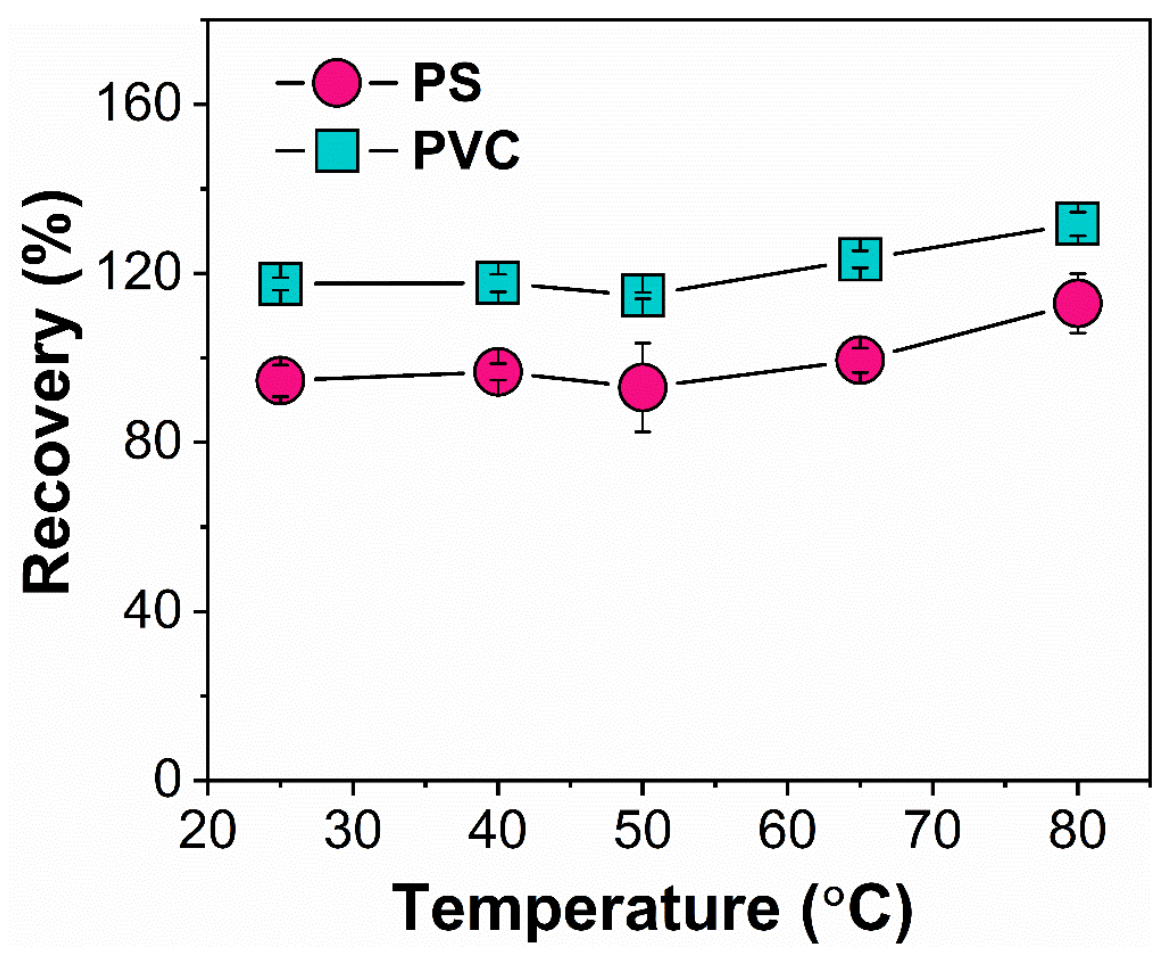

Figure S4. Effect of temperature on PS and PVC recovery. PS and PVC particles were added into pure water and incubated at water bath with different temperature for 3 hours, and then their contents were quantified by TOC analyzer after filtration with glass fiber 61 membrane.

62 


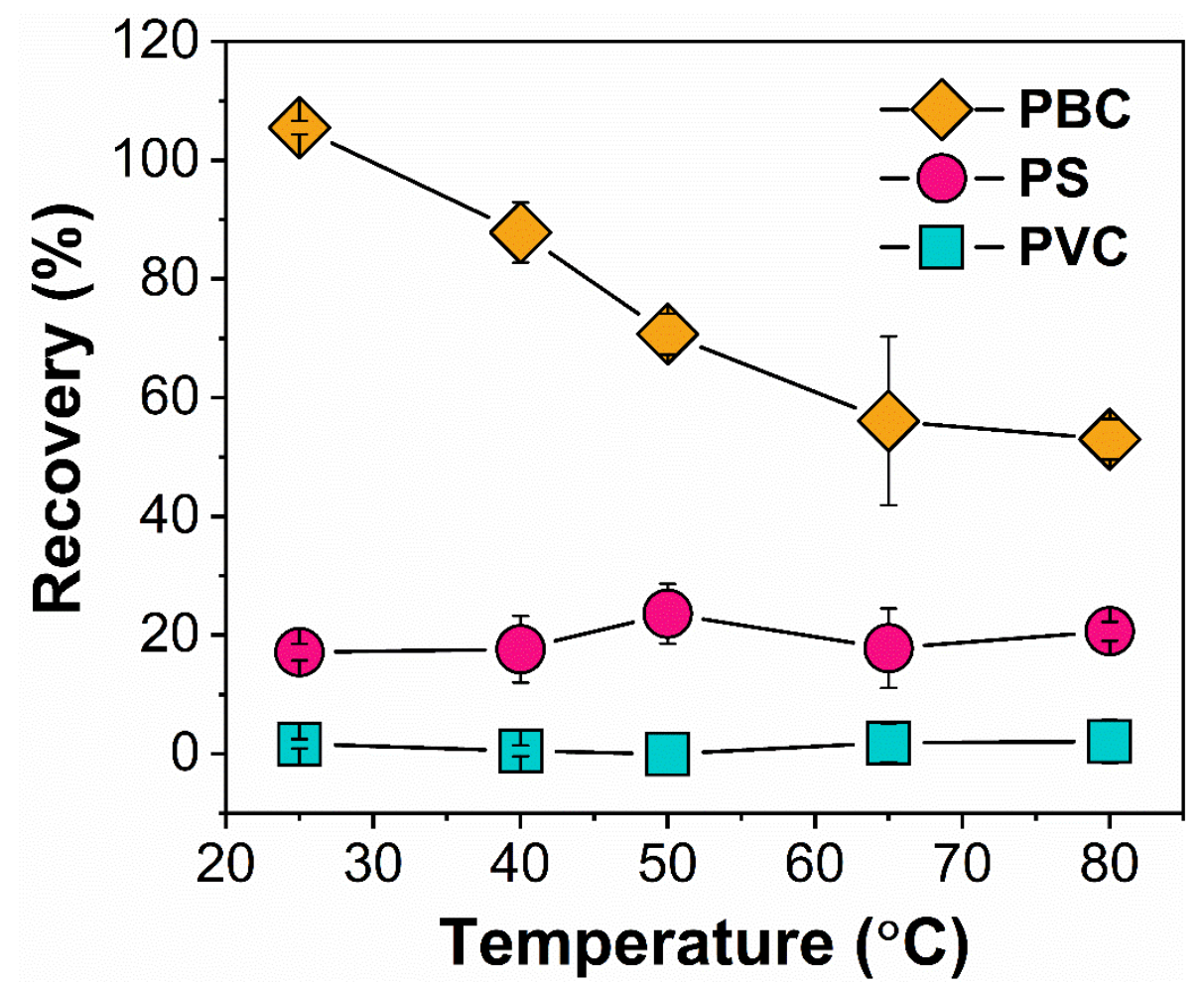

Figure S5. Impact of Fenton reaction temperature on digestion efficiency. The $100 \mathrm{~mL}$ of PVC, PS, PBC suspension (5 mg C/L) were treated by filtration and sulfonation under optimal conditions, and then subjected to Fenton digestion with $3.75 \mathrm{mmol} / \mathrm{L}$ $\mathrm{FeCl}_{3}$ for $12 \mathrm{~h}$ at different digestion temperature $\left(25,40,50,65\right.$ and $\left.80{ }^{\circ} \mathrm{C}\right)$. 


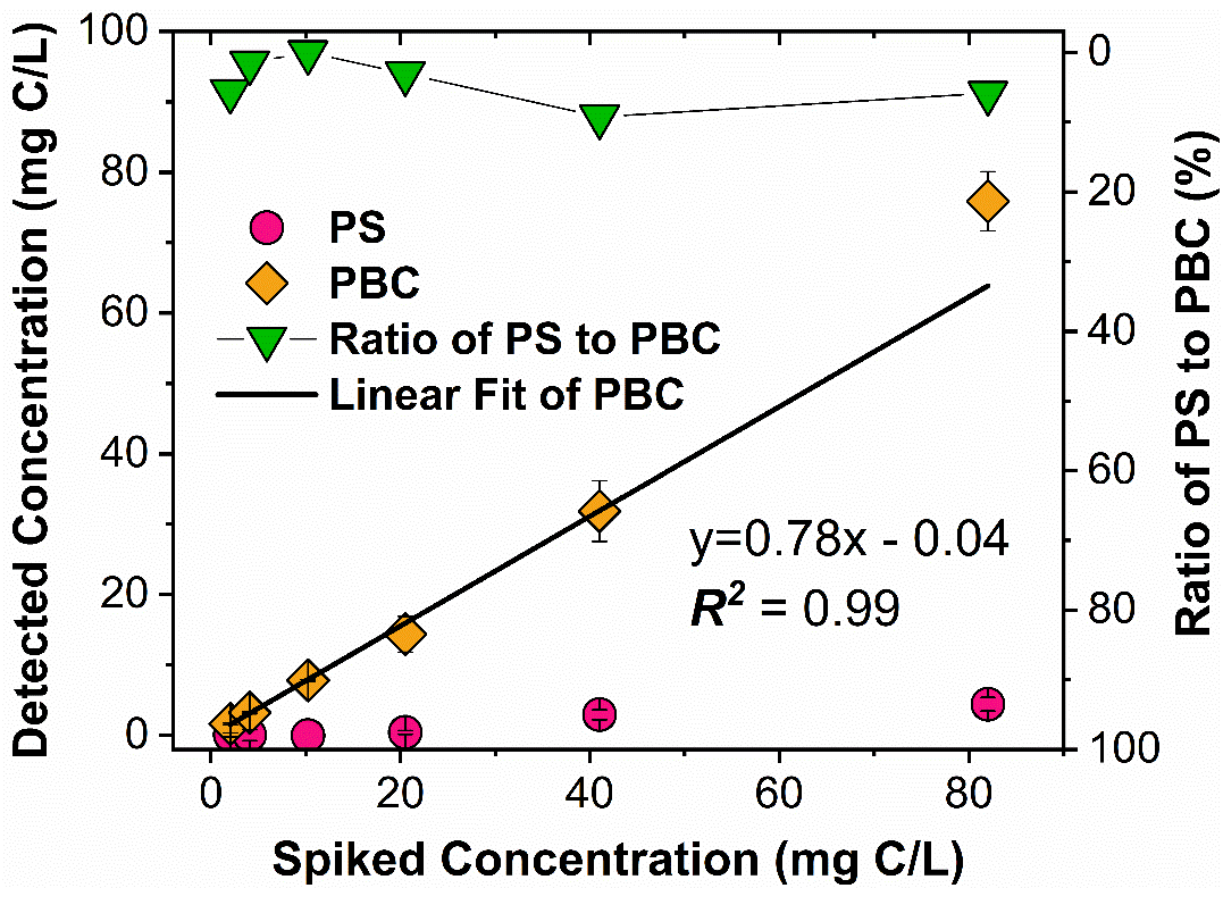

75

Figure S6. Effects of $\mathrm{PBC}$ and MPs concentration on $\mathrm{PBC}$ quantification. $\mathrm{PBC}$ and

77 MPs with different concentration were respectively spiked into $100 \mathrm{~mL}$ pure water, and 78 quantified by the proposed method. 
Table S1. Typical characteristics of the studied environmental waters.

\begin{tabular}{|c|c|c|c|c|c|c|c|}
\hline \multirow{2}{*}{ Sample } & \multirow{2}{*}{$\begin{array}{l}\text { TOC } \\
(\mathrm{mg} \mathrm{C} / \mathrm{L})\end{array}$} & \multirow{2}{*}{$\begin{array}{l}\text { PBC } \\
(\mu \mathrm{g} \mathrm{C} / \mathrm{L})\end{array}$} & \multirow{2}{*}{$\mathrm{pH}$} & \multicolumn{4}{|c|}{ Cations (mg/L) } \\
\hline & & & & $\mathrm{K}^{+}$ & $\mathrm{Na}^{+}$ & $\mathrm{Ca}^{2+}$ & $\mathrm{Mg}^{2+}$ \\
\hline Tap water & 4.19 & $22.3 \pm 3.1$ & 7.6 & $2.25 \pm 0.03$ & $11.18 \pm 0.02$ & $35.81 \pm 0.07$ & $9.95 \pm 0.08$ \\
\hline River water & 4.29 & $41.2 \pm 0.4$ & 7.4 & $2.17 \pm 0.09$ & $6.01 \pm 0.01$ & $35.38 \pm 0.13$ & $8.31 \pm 0.02$ \\
\hline Lake water & 6.96 & $67.9 \pm 33.5$ & 7.5 & $25.19 \pm 0.07$ & $93.01 \pm 0.38$ & $56.38 \pm 0.22$ & $20.36 \pm 0.06$ \\
\hline Seawater & 6.55 & $24.8 \pm 5.4$ & 7.6 & $343 \pm 3$ & $8193 \pm 304$ & $347 \pm 12$ & $1043 \pm 49$ \\
\hline
\end{tabular}

